\title{
Disparities in Caries Experience and Socio-Behavioural Risk Indicators Among Private School Children in Lagos, Nigeria
}

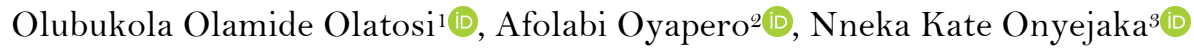

\begin{abstract}
${ }^{1}$ Department of Child Dental Health, Faculty of Dental Sciences, College of Medicine, University of Lagos.
${ }^{2}$ Department of Preventive Dentistry, Faculty of Dentistry, Lagos State University College of Medicine, Ikeja, Lagos, Nigeria.

${ }^{3}$ Department of Child Dental Health, University of Nigeria, Ituku, Enugu State, Nigeria.
\end{abstract}

Author to whom correspondence should be addressed: Dr Olatosi Olubukola O., Department of Child Dental Health, Faculty of Dental Sciences, College of Medicine, University of Lagos, Nigeria. Phone: 234-8071671410. E-mail: bukkyolatosi@gmail.com.

Academic Editors: Alessandro Leite Cavalcanti and Wilton Wilney Nascimento Padilha

Received: 15 February 2020 / Accepted: 01 May 2020 / Published: 08 June 2020

How to cite this article: Olatosi OO, Oyapero A, Onyejaka NK. Disparities in caries experience and socio-behavioural risk indicators among private school children in Lagos, Nigeria. Pesqui Bras Odontopediatria Clín Integr. 2020; $20: e 0023$. https://doi.org/10.1590/pboci.2020.102

\begin{abstract}
Objective: To determine the prevalence and socio-behavioural risk factors for dental caries among children at selected LGAs in Lagos State. Material and Methods: This was a descriptive study of 592 school children in four Local Government Areas of Lagos, Nigeria. The presence of caries was recorded using the World Health Organization criteria. Descriptive statistics were reported for analysis of comparative DMFT and $\mathrm{SiC}$ scores in relation to age, gender, and other socio-demographic variables. Logistic regression analysis was used to analyze the differential impact of the variables on the probability of being in the high caries prevalence group. Results: The prevalence of dental caries was $16.0 \%$ with mean dmft for age 6 being $1.3 \pm 1.57$ while the mean DMFT for age 12 was $0.15 \pm 0.67$. The mean Sic for age 6 was $1.5 \pm 0.53$ while the mean $\mathrm{SiC}$ for age 12 was $1.09 \pm 0.29$. The mean $\mathrm{SiC}$ values was significantly higher in the primary and permanent dentition among those who had never visited the dentist, female students, those who don't use fluoridated toothpaste and those who eat sweets and candy several times a day. After logistic regression analysis, those with no previous dental visit $(\mathrm{OR}=3.05$; CI: 1.72-4.67) and females (OR=1.55; CI: 1.16-1.62) still had significantly higher $\mathrm{SiC}$ Values. Conclusion: The prevalence of caries was low in the study population. Being female, non-use of fluoride-containing toothpaste and not visiting the dentist were significant predictors of dental caries among children attending private schools.
\end{abstract}

Keywords: Dental Caries; DMF Index; Prevalence; Dental Health Surveys; Risk Assessment. 


\section{Introduction}

Dental caries is one of the commonest dental conditions affecting children [1]. The aetiological factors of dental caries include refined sugar, plaque, tooth and the time of exposure [2]. Other associated risk indicators include socioeconomic status, brushing technique and frequency, use of fluoride containing toothpaste, perceived dental need, access to dental care, snacking habits and oral hygiene status [3-5]. The lesion formation and progression can however be halted through plaque control, fluoride use and modification of diet [6]. When dental caries is left untreated, it can affect the wellbeing of the child, negatively impact on oral related quality of life, as well as the productivity, development and educational performance [7].

An analysis of caries prevalence in many countries has often shown a skewed distribution of the disease with some groups of children having high or very high decayed/missing/filled teeth (DMFT) values, while the rest have low DMFT or are totally caries-free [8,9]. A lot of efforts have been made to reduce the incidence of caries but it is seen to be increasing in developing countries. In Nigeria, prevalence of dental caries among school children varies from $13.9 \%$ to $35.5 \%$ [10-12]. Most of these carious lesions remain untreated indicating that utilization of dental services is low in the country [13]. Traditional dental care remains a significant economic burden for many countries, where $5-10 \%$ of public health expenditure relates to oral health.

The World Health Organization (WHO) global goal of no more than an average of three DMFT (decayed, missing, filled teeth) at 12 years of age has been used as a global yardstick for oral health program success [8]. The DMFT/dmft scores provides a scoping view of population disease levels, but it may not reflect the significant burden of the disease experience in subsections of the population. The differences in the epidemiological pattern of caries within countries and the failure of DMFT index to provide information on the clinical consequences of untreated dental caries, such as pulpal abscess, which may be more serious than the carious lesions themselves, resulted in the development of other tools for the assessment of caries severity. In identifying high-risk groups, it is recommended to determine the significant caries (SiC) Index scores distribution among children.

Previous studies have shown that children from high socioeconomic classes have a higher incidence of dental caries than those from lower socioeconomic class [14] but some other authors found contrary findings from developed countries [15]. Such unequivocal findings are also obtainable from previous studies in Nigeria $[16,17]$. Private schools in Nigeria are fee paying schools unlike public schools implying that children attending private schools are more financially empowered than those in public schools and hence, can afford cariogenic diet more than those in public schools. To the best of our knowledge there are no data available about the SiC values for primary and permanent dentition among children from high socioeconomic status in Lagos, Nigeria. We hypothesized that there is a high caries risk group among children from high socioeconomic groups in Nigeria that could still have a high caries prevalence.

We thus aimed to determine the prevalence of caries and distribution of significant caries among children attending private schools in the cosmopolitan city of Lagos, Nigeria. We also aimed to identify the risk indicators associated with dental caries.

\section{Material and Methods}

Study Population and Study Design

This was a descriptive study conducted among primary and secondary school children attending private schools in Lagos. The study was conducted in four Local Government Areas (LGAs) of Lagos State 
(Surulere, Mushin, Lagos Mainland and Shomolu). Lagos state is located in the Southwestern geopolitical zone of Nigeria with an estimated population of 17 million and it is the economic center of the country. It shares boundaries with Ogun State both in the North and East and on the West by Benin Republic. In the South, it stretches for $180 \mathrm{~km}$ along the coast of the Atlantic Ocean and occupies an area of $3,577 \mathrm{sq} \mathrm{km}, 22 \%$ or $787 \mathrm{sq}$ $\mathrm{km}$ which consists of lagoons and creeks. It consists of 20 Local Government Areas (LGAs). According to the Lagos private schools census reports, there are 543, 503, 422 and 172 private schools in Mushin, Surulere, Shomolu and Lagos mainland LGAs, respectively [18].

Inclusion and Exclusion Criteria

The inclusion criteria was children and teenagers aged from 5-16 years whose parents agreed to partake in the research and who gave informed consent and assent where applicable. Children with physical or mental incapacity, those with disorders that made routine oral hygiene measures difficult, and hence are more predisposed to dental caries, those with any developmental dental anomaly and those with ongoing dental treatment were excluded.

\section{Sample Size Determination}

The sample size was calculated using the formula for descriptive cross-sectional study [19]. Using the formula: $\mathrm{Z} 2 \mathrm{pq} / \mathrm{e} 2$, where $\mathrm{Z}=1.96, \mathrm{p}=0.212$, from a $21.2 \%$ prevalence of dental caries from a previous study in Urban Lagos [20] $q=1-p$, e set at $5 \%$ margin of error.

The minimum calculated sample size was 256. To accommodate for $10 \%$ of non-responders, the sample size was $256+26=282$. The sample was finally increased to 600 school children in order to increase the power of the study and to make provision for the reduction in sample size when the Sic values are calculated for 6 and 12-year-old children.

\section{Sampling Technique}

A multistage sampling method was adopted to select the study participants. The first stage made use of simple random sampling (balloting) to select 4 LGAs (Surulere, Mushin, Lagos Mainland and Shomolu) out of the list of 20 LGAs in Lagos State.

The second stage involved the selection of one primary and one secondary school in one randomly selected ward utilizing the list of schools in the LGA obtained from the Lagos State Ministry of Education as the sampling frame, using computer generated random numbers. The 600 study participants were distributed among the private schools by stratified random sampling as follows: Primary 1 to primary 6 was used for primary school while Junior Secondary 1 to Senior Secondary3 was used for secondary school; 40 respondents were selected in each primary school and 35 respondents in each secondary school.

The third stage involved simple random sampling (balloting) for one class in each level in each selected school. This was done by balloting for 7 students in each arm selected in the primary schools and 6 students in each level selected in the secondary schools utilizing the class register as the sampling frame. Students who picked "yes" in the ballot and met the selection criteria were enlisted in the study, while those who picked "no".

\section{Data Collection}

Data was collected by dentists who were calibrated on the content of the questionnaires by a Consultant Community Dentist and a Consultant Paediatric Dentist. Intra examiner and extra examiner were 
assessed by examining 10 children with dental caries on two separate occasions with two weeks interval. The result was coded and entered into the computer. The data were then subjected to a Cohen's kappa scores analysis, to determine the intra-examiner and inter-examiner variability. The intra-examiner variability scores ranged from 0.80 to 0.85 while the inter-examiner variability scores ranged from 0.81 to 0.84 for the $\mathrm{DMFT} / \mathrm{dmft}$ indices.

An interviewer administered questionnaire was utilized for data collection. The data collection tool consisted of the section (A) which contained questions that elicited information on the socio demographic profile of the students (age of the study participants as at the last birthday, sex, mother's level of educational status, tribe, location of school). The second part elicited information on tooth brushing and its frequency, use of fluoride containing toothpaste, snacking habits, history of past dental visit, and smoking habit.

On the first day of the study, the children were given informed consent form with the first part of the questionnaire attached to it to give to their parents to fill at home. On the second day, oral examination was conducted on the children with signed informed consent forms after administering the questionnaire. Dental examination was conducted by the same trained dentists in the school premises under natural light. Caries status was assessed using the decayed, missing, and filled permanent teeth $\mathrm{dmft} / \mathrm{DMFT}$ index. The trained dentists specifically verified the cause of missing teeth for any child with a missing tooth. Specific questions asked included history of toothache, visit to the dentist, extraction of teeth at the dentist, and recall of tooth exfoliation. Where a history points to the cause of a missing tooth being due to extraction as a sequela to caries, the tooth is then charted as missing $(\mathrm{m})$ for the primary dentition or missing $(\mathrm{M})$ for the permanent dentition.

\section{Data Analysis}

Statistical Package of Social Science version 23.0 (IBM, Armonk, New York, USA) was used for data analysis. Descriptive analysis was conducted using a wide variety of measures of location (mean). The Mean DMFT and dmft scores for both primary and permanent dentition were reported while the SiC was calculated for children aged 6 and 12 years for the primary and permanent teeth respectively. Bivariate analysis was conducted to test the association between sex, age, mother's level of education, and occurrence of dental caries. The association between the behavioural factors and occurrence of dental caries was also conducted. A model was developed to determine predictors of dental caries. Logistic regression model controlled for variables that showed statistical significance $(\mathrm{p}<0.05)$ in bi-variate analysis with Sic and DMFT/ dmft as dependent variables. The probability level of $\mathrm{p}<0.05$ was considered statistically significant.

\section{Ethical Consideration}

Approval for the study was sought from and granted by the Health Research and Ethics Committee of the Lagos University Teaching Hospital (LUTH), Idi-Araba, Lagos, Nigeria (Protocol No. $\mathrm{ADM} / \mathrm{DCST} / \mathrm{HREC} / \mathrm{APP} / 672$ ). Consent was also obtained from students aged from the parents of all the children. Assent was similarly obtained from children aged 8 years and above. Permission to screen the students was obtained from the state ministry of education as well as the school head teachers.

\section{Results}

Table 1 displays the prevalence of caries among school children from previous Nigerian studies. 
Table 1. Prevalence of caries among school children from previous Nigerian studies.

\begin{tabular}{lcccll}
\hline \multicolumn{1}{c}{ Author } & Year & Private School & Public School & \multicolumn{1}{c}{ Location } & Age Group \\
\hline Alakija [21] & 1983 & $66.8 \%$ & $14 \%$ & Urban, Benin & $5-14$ Years \\
Ojofeitimi et al. [22] & 1984 & $48 \%$ & $24 \%$ & Semi-urban Ife-Ife & $8-15$ Years \\
Adenubi [23] & 1884 & $54 \%$ & $41.7 \%$ & Urban, Lagos & 8 Years \\
Sho-Silva [20] & 2004 & $25.5 \%$ & $22.4 \%$ & Urban, Lagos & $3-10$ Years \\
Sofola et al. [16] & 2004 & $21 \%$ & $8.1 \%$ & Urban and rural Lagos & $4-16$ Years \\
Adekoya-Sofowora et al. [14] & 2006 & $57.8 \%$ & $19.3 \%$ & Sub-urban Ile-Ife & 12 Years \\
Nnawuihe and Okeigbemen [24] & 2016 & $23.7 \%$ & $15.3 \%$ & Urban and Rural Edo & $4-21$ Years \\
Adeniyi et al. [25] & 2016 & $17.6 \%$ & $23.6 \%$ & Urban, Lagos & $5-10$ Years \\
Soroye and Braimoh [17] & 2016 & $8.7 \%$ & $10.7 \%$ & Urban, Lagos & $11-20$ Years \\
Kalejaiye [26] & 2016 & $20.4 \%$ & $38.5 \%$ & Urban, Ilorin & 12 Years \\
Eigbobo and Alade [27] & 2017 & $10.2 \%$ & $15 \%$ & Urban, Port Harcourt & $3-12$ Years \\
Adeniyi and Odusanya [28] & 2017 & $20.6 \%$ & $21.3 \%$ & Urban, Lagos & $8-12$ Years \\
\hline
\end{tabular}

Six hundred children were recruited for the study while five hundred and ninety-two school children with complete data were included in the final analysis. There were $307(51.9 \%)$ males and $285(48.1 \%)$ females. The age range was 5 to 16 years with mean age $10.8 \pm 2.4$ years. More than half $(69.3 \%)$ of the subjects were from the Yoruba ethnic group and most $(54.2 \%)$ of the children examined had visited the dentist prior to the study. The prevalence of dental caries was $16.0 \%$ with mean $\mathrm{dmft}$ for age 6 was $1.3 \pm 1.57$ while the mean DMFT for age 12 was $0.15 \pm 0.67$. The socio-demographic characteristics of the study population are displayed in Table 2 .

Table 2. Socio-demographic profile of study participants.

\begin{tabular}{|c|c|}
\hline Variables & $\begin{array}{c}\text { Frequency } \\
\mathrm{N}(\%)\end{array}$ \\
\hline \multicolumn{2}{|l|}{ Sex } \\
\hline Male & $307(51.9)$ \\
\hline Female & $285(48.1)$ \\
\hline \multicolumn{2}{|l|}{ Age (Years) } \\
\hline $5-11$ & $367(62.0)$ \\
\hline$>11$ & $225(38.0)$ \\
\hline \multicolumn{2}{|l|}{ Education of Mother } \\
\hline No Formal & $6(1.0)$ \\
\hline Primary & $32(5.4)$ \\
\hline Secondary & $203(34.3)$ \\
\hline Tertiary & $351(59.3)$ \\
\hline \multicolumn{2}{|l|}{ Ethnicity } \\
\hline Hausa & $4(0.7)$ \\
\hline Igbo & $124(20.9)$ \\
\hline Others & $54(9.1)$ \\
\hline Yoruba & $410(69.3)$ \\
\hline \multicolumn{2}{|l|}{ Previous Dental Visit } \\
\hline Yes & $321(54.2)$ \\
\hline No & $271(45.8)$ \\
\hline \multicolumn{2}{|l|}{ Caries } \\
\hline Yes & $95(16.0)$ \\
\hline No & $497(84.0)$ \\
\hline Total & $592(100.0)$ \\
\hline
\end{tabular}

There was significant association between the gender of the respondents $(\mathrm{p}=0.038)$ and presence of dental caries. More female (19.3\%) than males (13.0\%) had dental caries. Children in the younger age group 511 years had significantly higher mean dmft scores of $0.83 \pm 2.7$ than those $>1$ years with mean DMFT score of $0.13 \pm 0.49(p<0.001)$. There was no significant association between age $(p=0.061)$, ethnicity $(p=0.960)$, 
mother's level of education $(\mathrm{p}=0.492)$ and dental caries occurrence and DMFT index. The association between socio-demographic profile, caries occurrence and dmft/DMFT index is shown in Table 3.

Table 3. Association between socio-demographic profile, caries occurrence and mean DMFT/dmft.

\begin{tabular}{|c|c|c|c|c|c|c|}
\hline \multirow[b]{2}{*}{ Variables } & \multicolumn{2}{|c|}{ Dental Caries } & \multirow[b]{2}{*}{ p-value } & \multirow{2}{*}{$\begin{array}{c}\text { dmft } \\
\text { Mean (SD) }\end{array}$} & \multirow{2}{*}{$\begin{array}{c}\text { DMFT } \\
\text { Mean (SD) }\end{array}$} & \multirow[b]{2}{*}{ p-value } \\
\hline & $\begin{array}{c}\text { No } \\
\text { N (\%) }\end{array}$ & $\begin{array}{c}\text { Yes } \\
\text { N (\%) }\end{array}$ & & & & \\
\hline Overall Mean & & & & $1.3 \pm 1.57$ & $0.15 \pm 0.67$ & \\
\hline \multicolumn{7}{|l|}{ Gender } \\
\hline Male & $267(87.0)$ & $40(13.0)$ & $0.038^{*}$ & $0.90 \pm 3.01$ & $0.11 \pm 0.43$ & 0.958 \\
\hline Female & $230(80.7)$ & $55(19.3)$ & & $0.76 \pm 2.35$ & $0.16 \pm 0.55$ & \\
\hline \multicolumn{7}{|l|}{ Age (Years) } \\
\hline $5-11$ & $300(81.7)$ & $67(18.3)$ & 0.061 & $0.83 \pm 2.70$ & & $<0.001^{*}$ \\
\hline$>11$ & $197(87.6)$ & $28(12.4)$ & & & $0.13 \pm 0.49$ & \\
\hline \multicolumn{7}{|l|}{ Ethnicity } \\
\hline Hausa & $3(75.0)$ & $1(25.0)$ & 0.960 & $0.33 \pm 0.57$ & - & 0.997 \\
\hline Igbo & $105(84.7)$ & $19(15.3)$ & & $0.74 \pm 2.40$ & $0.13 \pm 0.55$ & \\
\hline Others & $45(83.3)$ & $9(16.7)$ & & $0.83 \pm 2.70$ & $0.13 \pm 0.49$ & \\
\hline Yoruba & $344(83.9)$ & $66(16.1)$ & & $0.84 \pm 2.82$ & $0.11 \pm 0.42$ & \\
\hline \multicolumn{7}{|c|}{ Mother's Level of Education } \\
\hline No Formal & $5(83.3)$ & $1(16.7)$ & 0.492 & $0.25 \pm 0.50$ & - & 0.381 \\
\hline Primary & $28(87.5)$ & $4(12.5)$ & & $1.00 \pm 1.73$ & $0.05 \pm 0.23$ & \\
\hline Secondary & $164(80.8)$ & $39(19.2)$ & & $1.05 \pm 2.06$ & $0.05 \pm 0.24$ & \\
\hline Tertiary & $300(85.5)$ & $51(14.5)$ & & $0.65 \pm 2.23$ & $0.14 \pm 0.53$ & \\
\hline Total & $497(84.0)$ & $95(16.0)$ & & & & \\
\hline
\end{tabular}

*Statistically significant.

Respondents who used fluoride-containing toothpaste had a significantly lower caries prevalence than those who did not use fluoride-containing toothpaste $(\mathrm{p}=0.039)$. There was no significant association between previous dental visit $(p=0.091)$, frequency of brushing $(p=0.696)$, cigarette smoking $(p=0.295)$, sugar snacks (0.770), sugar drinks $(\mathrm{p}=0.510)$ and dental caries. The association between behavioural factors, caries occurrence and mean DMFT/dmft are displayed in Table 4.

Table 4. Association between behavioural factors, caries occurrence and mean DMFT/dmft.

\begin{tabular}{|c|c|c|c|c|c|c|}
\hline \multirow[b]{2}{*}{ Variables } & \multicolumn{2}{|c|}{ Dental Caries } & \multirow[b]{2}{*}{ p-value } & \multirow{2}{*}{$\begin{array}{c}\text { dmft } \\
\text { Mean (SD) }\end{array}$} & \multirow{2}{*}{$\begin{array}{c}\text { DMFT } \\
\text { Mean (SD) }\end{array}$} & \multirow[b]{2}{*}{ p-value } \\
\hline & $\begin{array}{c}\text { No } \\
\mathrm{N}(\%)\end{array}$ & $\begin{array}{c}\text { Yes } \\
\mathrm{N}(\%)\end{array}$ & & & & \\
\hline \multicolumn{7}{|l|}{ Previous Dental Visit } \\
\hline Yes & $277(86.3)$ & $44(13.7)$ & 0.091 & $0.66 \pm 2.64$ & $0.06 \pm 0.34$ & 0.903 \\
\hline No & $220(81.2)$ & $51(18.8)$ & & $1.37 \pm 3.65$ & $0.81 \pm 2.67$ & \\
\hline \multicolumn{7}{|c|}{ Frequency of Cleaning Teeth } \\
\hline Not Everyday & $50(87.7)$ & $7(12.3)$ & 0.696 & $1.27 \pm 3.87$ & $0.21 \pm 0.69$ & 0.903 \\
\hline Once a Day & $235(83.9)$ & $45(16.1)$ & & $0.50 \pm 1.09$ & $0.30 \pm 0.87$ & \\
\hline 2 or More per Day & $212(83.1)$ & $43(16.9)$ & & $0.60 \pm 1.34$ & $0.27 \pm 0.97$ & \\
\hline \multicolumn{7}{|l|}{ Fluoride } \\
\hline Yes & $348(84.1)$ & $66(15.9)$ & 0.039 & $0.73 \pm 2.39$ & $0.15 \pm 0.53$ & \\
\hline No & $137(77.0)$ & $41(23.0)$ & & $1.25 \pm 3.68$ & $0.11 \pm 0.43$ & \\
\hline \multicolumn{7}{|l|}{ Cigarette } \\
\hline Never & $496(84.1)$ & $94(15.9)$ & 0.295 & $0.47 \pm 2.70$ & $0.13 \pm 0.47$ & 0.999 \\
\hline Yes & $1(50.0)$ & $1(50.0)$ & & $0.83 \pm 2.70$ & $0.14 \pm 0.49$ & \\
\hline \multicolumn{7}{|l|}{ Sugar Snacks } \\
\hline Never & $30(85.7)$ & $5(14.3)$ & 0.770 & $0.38 \pm 0.96$ & $0.06 \pm 0.24$ & \\
\hline Yes & $467(83.8)$ & $90(16.2)$ & & $1.81 \pm 4.51$ & $0.17 \pm 0.57$ & \\
\hline \multicolumn{7}{|l|}{ Sugar Drinks } \\
\hline Never & $53(86.9)$ & $8(13.1)$ & 0.510 & $0.31 \pm 0.84$ & $0.13 \pm 0.43$ & \\
\hline Yes & $444(83.6)$ & $87(16.4)$ & & $1.61 \pm 4.02$ & $0.17 \pm 0.48$ & \\
\hline
\end{tabular}


Table 5 shows the result of the logistic regression analysis for the best predictor of dental caries. Gender and use of fluoridated toothpastes were significant predictors $(p=0.047$ and $p=0.041)$ of dental caries respectively. Females had a 57.0\% $(\mathrm{OR}=1.57, \mathrm{CI}=1.005-2.452, \mathrm{p}=0.047)$ increased odd of having dental caries when compared to males while those who did not use fluoridated toothpaste had $57.8 \%(\mathrm{OR}=1.58$, CI $=1.019$ 2.443, $\mathrm{p}=0.041)$ increased odds of having caries. Age was not a significant predictor $(\mathrm{p}=0.084)$ although children more than 11 years old had $36.0 \%$ decreased odd of having dental caries when compared to children aged 5-11years. Children who had no previous dental visit had 40.0\% increased odd of having dental caries when compared to those with previous dental visit. This was not statistically significant $(\mathrm{p}=0.138)$.

Table 5. Logistic regression analysis of effect of factors affecting occurrence of dental caries.

\begin{tabular}{|c|c|c|c|c|}
\hline Variables & $\mathbf{N}(\%)$ & Multivariate Adjusted OR & $95 \% \mathrm{CI}$ & p-value \\
\hline \multicolumn{5}{|l|}{ Gender } \\
\hline Male & $307(51.9)$ & 1.00 & & \\
\hline Female & $285(48.1)$ & 1.57 & $1.005-2.452$ & $0.047^{*}$ \\
\hline \multicolumn{5}{|l|}{ Age (Years) } \\
\hline $6-11$ & $367(62.0)$ & 1.00 & & \\
\hline$>11$ & $225(38.0)$ & 0.66 & $0.406-1.058$ & 0.084 \\
\hline \multicolumn{5}{|c|}{ Previous Dental Visit } \\
\hline Yes & $321(54.2)$ & 1.00 & & \\
\hline No & $271(45.8)$ & 1.40 & $0.898-2.182$ & 0.138 \\
\hline \multicolumn{5}{|l|}{ Fluoride } \\
\hline Yes & $414(69.9)$ & 1.00 & & \\
\hline No & $178(30.1)$ & 1.58 & $1.019-2.443$ & $0.041 *$ \\
\hline
\end{tabular}

The mean Sic for age 6 was $1.5 \pm 0.53$ while the mean $\mathrm{SiC}$ for age 12 was $1.09 \pm 0.29$. The mean Sic values was significantly higher in the primary and permanent dentition among those who had never visited the dentist, female students, those who don't use fluoridated toothpaste and those who eat sweets and candy several times a day. After logistic regression analysis, those with no previous dental visit (OR=3.05; CI: $1.72-$ 4.67) and females (OR=1.55; CI: 1.16-1.62) still had significantly higher Sic Values (Table 6).

Table 6. Association between Sic caries in primary and permanent dentition and demographic variables.

\begin{tabular}{|c|c|c|c|c|}
\hline Variables & Sic dmft & SIC DMFT & $\mathbf{F}$ & p-value \\
\hline Overall Mean & $1.17 \pm 0.37$ & $1.13 \pm 0.28$ & 3.506 & $<0.001^{*}$ \\
\hline Dental Visit - Never & $1.24 \pm 0.43$ & $1.17 \pm 0.38$ & 3.688 & $0.003^{*}$ \\
\hline Gender - Male & $1.13 \pm 0.34$ & $1.08 \pm 0.27$ & 1.34 & $0.026^{*}$ \\
\hline Female & $1.21 \pm 0.41$ & $1.09 \pm 0.29$ & & \\
\hline Fluoridated Toothpaste & $1.25 \pm 0.52$ & $1.14 \pm 0.41$ & 0.859 & $0.049^{*}$ \\
\hline Sweets and Candy - Several Times a Day & $1.22 \pm 0.42$ & $1.27 \pm 0.53$ & 2.776 & $0.011^{*}$ \\
\hline Regression & & OR & CI & \\
\hline Dental Visit - Never & & 3.05 & $1.72-4.67$ & $0.014^{*}$ \\
\hline Gender - Female & & 1.55 & $1.16-1.62$ & $<0.001^{*}$ \\
\hline
\end{tabular}

*Statistically significant.

Figure 1 shows that right mandibular second primary molar had the highest prevalence of caries 15 $(16.9 \%)$ while the maxillary central incisors had no caries o (0.0\%).

Figure 2 shows that the right mandibular first permanent molar has the highest caries occurrence while many other permanent teeth did not have caries. 


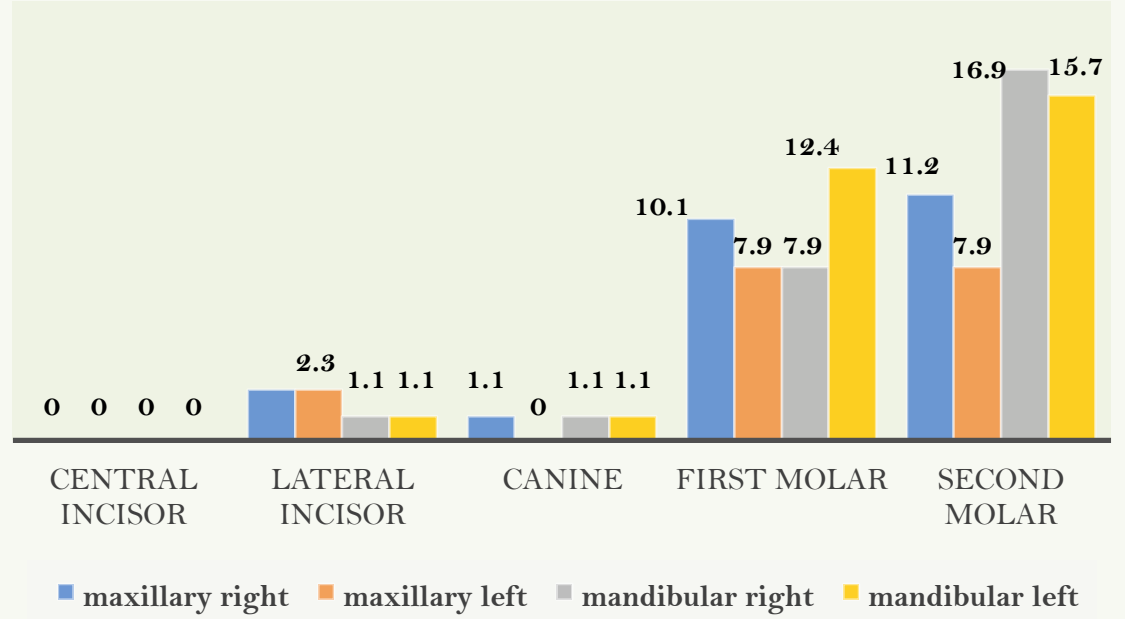

Figure 1. Caries prevalence according to tooth type in the primary dentition.

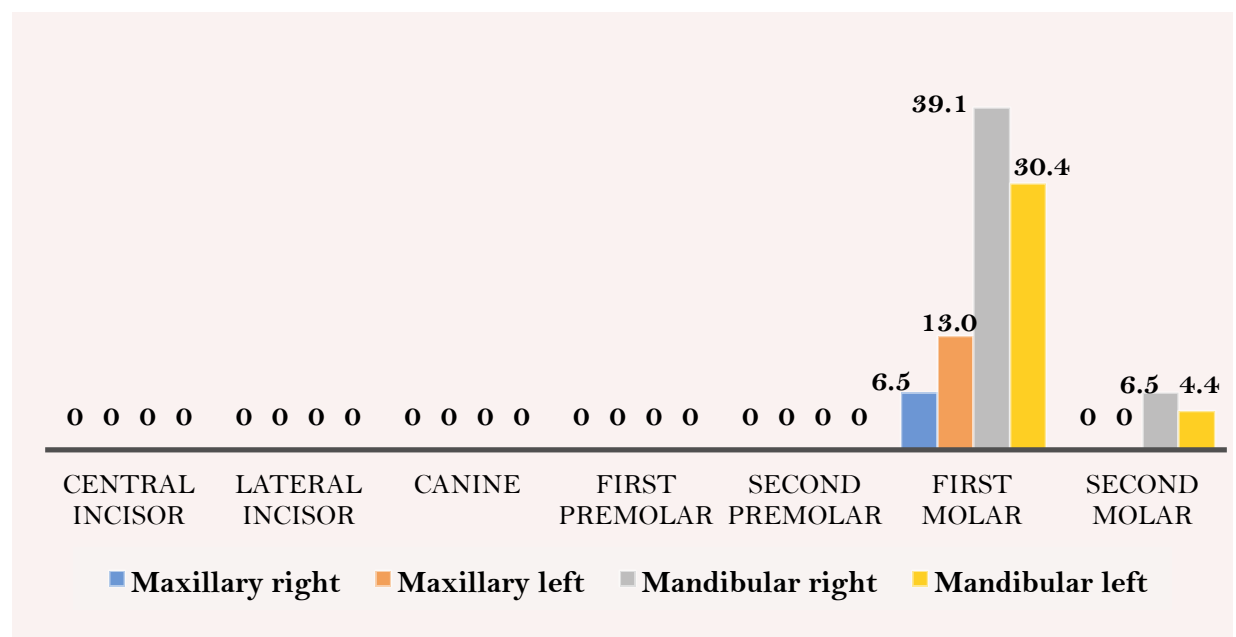

Figure 2. Caries prevalence according to tooth type in the permanent dentition.

\section{Discussion}

Several hours are reportedly lost each year all over the world at home, at work, and in schools due to the impact of oral diseases. The school environment provides the needed setting to carry out both preventive and curative oral health services [29]. The school environment creates opportunities for regular oral health education, screening exercises, prompt diagnosis and referral of children with oral diseases for treatment. It also has the potential to reach children and their families across social and cultural spectrum [30]. This study presents the caries experience and the socio-demographic and behavioural indicators of caries among a group of private school children in Lagos.

In Nigeria, schools are classified as either private or public depending on the source of their funding. Public schools are funded by the government and tuition fees are subsidized while private schools are funded by individual and high tuition fees are charged. The type of school a child attends depends on the environment where the child lives and the parent's socioeconomic status. Most children from high and middle socioeconomic family status attend private schools while children from low income family status attend public schools. The major reason for this difference in the choice of school is finance [14]. Caries experience have been associated with location and type of school [14]. Previous Nigerian studies have shown that children who attend private 
schools have a higher dmft than those who attended public schools [21,23,31,32]. This was attributed to the fact that children attending private schools have a higher socioeconomic status than those who attended public non-fee-paying schools, and thus have access to refined carbohydrates than those in public schools.

A decline in the prevalence of dental caries over the past three decades among children attending private schools in Nigeria has been obtained by different researchers over the last three decades (Table 1). Higher prevalence rates were reported among children in private schools than in public schools in the $1960 \mathrm{~s}$ and $80 \mathrm{~s}$ in Nigeria, while more recent reports indicate low prevalence [14,16,33,34]. These results appear to be in agreement with studies done in other developing countries [35-37]. This decline may be attributed to increased awareness among the children, parents and teachers probably due to more access to internet and more access to dental care at an earlier age [30], wide availability of fluoride containing toothpastes, an increase in oral health campaigns and school visits by paediatric dentists and other dental professionals; which possibly led to an improved health seeking behavior among parents from the high socioeconomic classes who can afford dental care. This change in the trend, with a higher prevalence of caries among children in public schools appears to be related to low socioeconomic status and access to dental care.

The prevalence of dental caries among our study population was $16 \%$, and this was comparable with similar studies conducted among private school children in urban and semi-urban settings (15.4\% Port Harcourt [38], 15.7\% Benin, 17.6\% Lagos [31]); but much lower when compared to that reported in Ibadan $(46 \%)$ and Lagos $(54 \%)$ and $66.8 \%$ [21,23,32] in their study conducted among private school children. The result from our study showed a low caries experience among children attending private schools and this is similar to other recent studies where a lower caries prevalence among children attending private schools [17,26-28]. A trend analysis of the prevalence of caries among Nigerian children has however been difficult, because the studies were conducted in different age groups is using different methods, among diverse populations and settings. We thus hypothesized that that distributions of significant caries exists among children from private schools who represent a cross section of children from high socioeconomic classes. We also hypothesized that there are certain risk indicators among these group which if identified could enable the design of appropriate interventions for this population.

Among our study subjects, the mean dmft in the primary dentition was $1.3 \pm 1.57$ while the mean DMFT at age 12 was very low at $0.15 \pm 0.67$, indicating a higher caries experience in early childhood than in adolescence; this was in tandem with a previous study conducted in Lagos [12]. In another study among school children in Lagos, the prevalence of untreated caries was highest among the younger age groups and this increased by $4.4 \%$ within a space of 3 years [5]. Therefore, any preventive oral care for school children in Lagos State should target children between 5-10 years. This result, however, contrasts with that obtained in Edo and Enugu states, in Nigeria [11,33], where older children had more carious lesions.

It is remarkable that more than half of the study participants had previously utilized dental services as observed in previous studies [14] even though it was mainly for curative rather than preventive purposes. We also observed that caries occurrence was significantly higher in females than males. This was similar to findings in previous studies $[11,39,40]$. This may be as a result of early eruption of teeth by females [41] and subsequent exposure to cariogenic diet than the teeth of males. It has also been shown that salivary flow rate is low in females, resulting in decreased buffering and remineralizing actions of saliva [42] with the consequences of developing caries.

A higher caries prevalence was observed among those who frequently consumed sugar containing snacks and drinks, although this association was not significant unlike prior studies [3,5]. Frequent 
consumption of cariogenic diet results in decrease in $\mathrm{pH}$, resulting in demineralization of the teeth leading to caries. There was a significantly lower prevalence of caries among those who used fluoridated toothpaste than those who did not among the study participants, Fluoride has been shown to be highly efficacious in reducing dental caries because of multiplicity of topical and systemic actions [43]. Regular use of fluoride toothpaste has been well documented to be associated with clear reduction in caries increment. Continuous efforts should be made to improve access to fluoridated toothpastes in Nigeria since less than $10 \%$ of the Nigerian population have access to tap water [44], making water fluoridation a less desirable option.

The highest tooth-specific caries prevalence was observed in the mandibular molars in both the primary and permanent dentitions. This may be attributed to food packing and plaque accumulation potentials in the lower molars which predispose to caries if not properly cleaned. In primary dentition, mandibular second molars were mostly affected. This agrees with the findings of previous studies [27,40], but contrary to the study in Enugu [3] in which dental caries occurred more in mandibular first primary molar. This difference may be as a result of the difference in the age distribution of the study participants in the diverse studies. In permanent dentition, mandibular first molars were affected the most probably because they are one of the earliest teeth to erupt and are exposed to cariogenic diet longer than other permanent teeth. The placement of fissure sealants is strongly advocated in these susceptible teeth [45].

When the study population was disaggregated, the mean Sic at age 6 in the primary dentition was 1.5 \pm 0.53 while the mean $\mathrm{SiC}$ for age 12 in the permanent dentition was $1.09 \pm 0.29$. The difference between the mean $\mathrm{dmft}$ and SIC values in the primary dentition was negligible (dmft: $1.3 \pm 1.57$; SiC: $1.5 \pm 0.53)$ while the difference between the mean DMFT and $\mathrm{SiC}$ at age 12 was significant (DMFT: $0.15 \pm 0.67$; SiC: $1.09 \pm 0.29$ ). Our results illustrate a uniform caries experience in early childhood but a higher caries experience among a select few in the early teenage years. This indicates that adequate effort should be made to identify young teenagers that have a higher caries experience. The mean $\mathrm{SiC}$ values was significantly higher among those who had never visited the dentist, female students, those who don't use fluoridated toothpaste and those who eat sweets and candy several times a day. After logistic regression analysis, those with no previous dental visit and females still had significantly higher SiC values. Thus in our resource limited environment, we should actively promote the use of fluoridated toothpaste and also increase access to dental care especially among female children

Apart from being one of the few studies that determined the risk indicators associated with $\mathrm{SiC}$ in Nigeria, the other strength of our investigation lies in our large sample size and our representative sample. This investigation, however, had a number of limitations. One is non-use of radiographs in identification of caries in the schools, even though we adhered to the WHO protocol for clinical diagnosis. Secondly, we focused on only private schools due to our concerns about the public health consequences associated with the general perception that caries prevalence has declined among this population. Nevertheless, within the limits of our study design, the data provides useful information for further empirical studies on subsets of the population that still have a high caries experience.

\section{Conclusion}

The prevalence of dental caries was low in our study population but caries experience was significantly higher among females, those who do not use of fluoridated toothpaste and those with poor dental clinic attendance. There decreasing trend in the prevalence of dental caries among children attending private 
schools in Lagos should however alert researchers to the possibility that some high risk populations may be overlooked when data is not disaggregated.

\section{Authors' Contributions}

\begin{tabular}{|c|c|c|c|}
\hline $\mathrm{OOO}$ & (iD) $0000-0003-1395-8261$ & $\begin{array}{l}\text { Conceptualization, Methodology, Investigation, Formal Analysis, } \\
\text { Original Draft Preparation and Writing - Review and Editing. }\end{array}$ & Writing \\
\hline $\mathrm{AO}$ & (iD) $0000-0003-4433-8276$ & $\begin{array}{l}\text { Conceptualization, Methodology, Investigation, Formal Analysis, } \\
\text { Original Draft Preparation and Writing - Review and Editing. }\end{array}$ & Writing \\
\hline NKO & (iD) $0000-0001-8926-056 \mathrm{X}$ & $\begin{array}{l}\text { Conceptualization, Methodology, Investigation, Formal Analysis, } \\
\text { Original Draft Preparation and Writing - Review and Editing. }\end{array}$ & Writing \\
\hline
\end{tabular}

\section{Financial Support}

None.

\section{Conflict of Interest}

The authors declare no conflicts of interest.

\section{References}

[1] Selwitz RH, Ismail AI, Pitt NB. Dental caries. Lancet 2007; 369(9555):51-9. https://doi.org/10.1016/So140-6736(07)60031-2

[2] Basavaraj P, Khuller N, Khuller RI, Sharma N. Caries risk assessment and control. J Oral Heal Community Dent $2011 ; 5(2): 58-63$. https://doi.org/10.5005/johcd-5-2-58

[3] Onyejaka NK, Amobi EO. Risk factors of early childhood caries among children in Enugu, Nigeria. Brazilian Res Paediatr Dent Integr Clin 2016;16(1):381-91. https://doi.org/10.4034/PBOCI.2016.161.40

[4] Folayan MO, Kolawole KA, Oziegbe EO, Oyedele T, Oshomoji OV, Chukwumah NM, et al. Prevalence, and early childhood caries risk indicators in preschool children in suburban Nigeria. BMC Oral Health 2015; 15:72. https://doi.org/10.1186/s 12903-015-0058-y

[5] Olatosi OO, Inem V, Sofola OO, Prakash P, Sote EO. The prevalence of early childhood caries and its associated risk factors among preschool children referred to a tertiary care institution. Niger J Clin Pract 2015; 18(4):493-501. https://doi.org/10.4103/1119-3077.156887

[6] Martins-Júnior PA, Vieira-Andrade RG, Corrêa-Faria P, Oliveira-Ferreira F, Marques LS, Ramos-Jorge ML. Impact of early childhood caries on the oral health-related quality of life of preschool children and their parents. Caries Res 2013; 47(3):211-8. https://doi.org/doi: 10.1159/000345534

[7] Sheiham A. Dental caries affects body weight, growth and quality of life in pre-school children. Br Dent J 2006; 201(10):625-6. https://doi.org/10.1038/sj.bdj.4814259

[8] World Health Organization. Oral Health Country/Area Profile Programme. Available from: http://www.whocollab.od.mah.se/index.html. [Accessed on May 22, 2019].

[9] Nishi M, Stjernswärd J, Carlsson P, Bratthall D. Caries experience of some countries and areas expressed by the Significant Caries Index. Community Dent Oral Epidemiol 2002; 30(4):296-301. https://doi.org/10.1034/j.16000528.2002.00054.x

[10] Denloye O, Ajayi D, Bankole O. A Study of dental caries prevalence in 12-14 year old school children in Ibadan, Nigeria. Pediatr Dent J 2005; 15(2):147-51. https://doi.org/10.1016/So917-2394(05)70045-8

[11] Udoye C, Aguwa E, Chikezie R, Ezeokenwa M, Jerry-Oji O, Okpaji C. Prevalence and distribution of caries in the 1215 year urban school children in Enugu, Nigeria. Internet J Dent Sci 2008; 7(2):1-5.

[12] Adeniyi AA, Sofola OO, Kalliecharan RV. An appraisal of the oral health care system in Nigeria. Int Dent J 2012; 62:292-300. https://doi.org/10.1111/j.1875-595X.2012.00122.x

[13] Onyejaka NK, Folayan MO, Folaranmi N. Effect of referral for dental service on dental- service utilization by primary school children aged 8 to 11 years in Enugu, Nigeria. Brazilian J Oral Sci 2016; 15(2):151-7. https://doi.org/10.20396/bjos.v15i2.8648767

[14] Adekoya-Sofowora CA, Nasir WO, Oginni AO, Taiwo M. Dental caries in 12-year-old suburban nigerian school children. Afr Health Sci 2006; 6(3):145-50. https://doi.org/ 10.5555/afhs.2006.6.3.145

[15] Petersson GH, Bratthall D. The caries decline: a review of reviews. Eur J Oral Sci 1996; 104(4):436-43. https://doi.org/10.1111/j.1600-0722.1996.tbo0110.x 
[16] Sofola OO, Jeboda SO, Shaba OP. Dental caries status of primary school children aged 4-16 years in southwestern, Nigeria. Odontostomatol Trop 2004; 27(108):19-22.

[17] Soroye MO, Braimoh OB. Oral health status of children in government and private secondary schools in Lagos state, Nigeria. Niger J Dent Res. 2016; 1(1-2):34-40.

[18] Härmä J. Lagos private school census 2010-11 report: report number LG 501. Educ Sect Support Program Niger $2011 ; 23-7$.

[19] Kasiulevičius V, Šapoka V, Filipavičiūtè R. Sample size calculation in epidemiological studies. Gerontologija 2006; $7(4): 225-31$.

[20] Sho-Silva VE. Pattern of caries in children age 3-10 years: a study of the private and public school children in Surulere Local Government Area. [Dissertation]. Faculty of Surgery: National Postgraduate Medical College of Nigeria; 2004.

[21] Alakija W. Dental caries in primary school children in Benin City, Nigeria. J Trop Pediatr 1983; $29(6): 317-9$. https://doi.org/10.1093/tropej/29.6.317

[22] Ojofeitimi EO, Hollist NO, Banjo T, Adu TA. Effect of cariogenic food exposure on prevalence of dental caries among fee and non-fee paying Nigerian school children. Community Dent Oral Epidemiol 1984; 12(4):274-7. https://doi.org/10.1111/j.1600-0528.1984.tbo 1454.x

[23] Adenubi JO. Caries experience of 8-year-old Nigerian schoolchildren. Community Dent Oral Epidemiol 1984; 12(5):343-8. https://doi.org/10.1111/j.1600-0528.1984.tbo1467.x

[24] Nnawuihe UC, Okkeigbemen SA. An assessement of dental caries and periodontal disease burden in selected primary and secondary school children in Edo state, Southern-Nigeria. Nig J Dent Res 2016; 1(1-2):28-33.

[25] Adeniyi AA, Oyapero OA, Ekekezie OO, Braimoh MO. Dental caries and nutritional status of school children in Lagos, Nigeria - a preliminary survey. J West Afr Coll Surg 2016; 6(3):15-38.

[26] 26. Kalejaiye HA, Adeyemi MF, Akinshipo A, Sulaiman AO, Braimah RO, Ibikunle AA, et al. Prevalence of dental caries and pattern of sugar consumption among junior secondary school students in Northcentral Nigeria. Niger J Exp Clin Biosci 2016; 4:13-8. https://doi.org/10.4103/njecp.njecp_19_16

[27] Eigbobo JO, Alade G. Dental caries experience in primary school pupils in Port Harcourt, Nigeria. Sahel Med J 2017; 20:179-86. https://doi.org/10.4103/smj.smj_70_15

[28] Adeniyi AA, Odusanya OO. Self-reported dental pain and dental caries among 8-12-year-old school children: an exploratory survey in Lagos, Nigeria. Niger Postgrad Med J 2017; 24(1): 37-43. https://doi.org/10.4103/npmj.npmj_7_17

[29] Folayan MO, Adeniyi AA, Chukwumah NM, Onyejaka N, Esan AO, Sofola OO, et al. Programme guidelines for promoting good oral health for children in Nigeria: a position paper. BMC Oral Health 2014; 14:128. https://doi.org/10.1186/1472-6831-14-128

[30] 30. Popoola BO, Denloye OO, Iyun OI. Influence of parental socioeconomic status on caries prevalence among children seen at the University College Hospital, Ibadan. Ann Ibadan Postgrad Med 2013; 11(2):81-6.

[31] Chukwumah NM, Azodo CC, Adeghe HA, Enabulele JE. Relating dental caries experience with body mass index among Nigerian primary school children: a cross sectional survey. J Educ Ethics Dent. 2012; 2(1):28-32.

[32] Noah MO. The prevalence and distribution of dental caries in the deciduous dentition and the state of oral cleanliness in 6-year-old Ibadan children attending private schools. Odontostomatol Trop. 1981; 4(2):113-20.

[33] Okeigbemen SA. The prevalence of dental caries among 12 to 15-year-old school children in Nigeria: report of a local survey and campaign. Oral Health Prev Dent 2004; 2(1):27-31.

[34] Umesi-Koleoso DC, Ayanbadejo PO, Oremosu OA. Dental caries trend among adolescents in Lagos, South-West Nigeria. West Afr J Med 2007; 26(3):201-5. https://doi.org/10.4314/wajm.v26i3.28309

[35] Addo-Yobo C, Williams SA, Curzon MEJ. Dental caries experience in Ghana among 12-year-old urban and rural schoolchildren. Caries Res 1991; 25(4):311-4. https://doi.org/10.1159/000261382

[36] Cleaton-Jones P, Fatti P, Bonecker M. Dental caries trends in 5- to 6-year- old and 11- to 13-year-old children in three UNICEF designated regions - Sub Saharan Africa, Middle East and North Africa, Latin America and Caribbean: 1970-2004. Int Dent J 2006; 56(5):294-300. https://doi.org/10.1111/j.1875-595x.2006.tbo0104.x

[37] Bajomo AS, Rudolph MJ, Ogunbodede EO. Dental caries in six, 12 and 15 year old Venda children in South Africa. East Afr Med J 2004; 81(5):236-43. https://doi.org/10.43 14/eamj.v81i5.9166

[38] Braimoh OB, Umanah AU, Ilochonwu NA. Caries distribution, prevalence, and treatment needs among 12-15-yearold secondary school students in Port Harcourt, Rivers State, Nigeria. J Dent Surg 2014; 2014:1-6. https://doi.org/10.1155/2014/483760

[39] Sowole CA, Sote EO. Breastfeeding, bottle feeding and caries experience in children aged 6 months to 5 years in Lagos state, Nigeria. African J Oral Health 2006; 2(1):43-56. https://doi.org/10.4314/ajoh.v3i1-2.57026

[40] Iyun OI, Denloye OO, Bankole OO, Popoola BO. Prevalence and pattern of early childhood caries in Ibadan, Nigeria. African J Med Sci 2014; 43(3):23-44.

[41] Demirci M, Tuncer S, Yuceokur AA. Prevalence of caries on individual tooth surfaces and its distribution by age and gender in University Clinic Patients. Eur J Dent 2010; 4(3):270-9.

[42] Eliasson L, Birkhed D, Osterberg T, Carlen A. Minor salivary gland secretion rates and immunoglobulin A in adults 
and the elderly. Eur J Oral Sci 2006; 114(6):494-9. https://doi.org/10.1111/j.1600-0722.2006.00413.x

[43] Arends J, Nelson DGA, Dijkman AG, Jongebloed WL. Effect of various fluorides on enamel structure and chemistry. Cariol Today 1984:245-58. https://doi.org/10.1159/000408745

[44] Akpata ES, Danfillo IS, Otoh EC, Mafeni JO. Geographical mapping of fluoride levels in drinking water sources in Nigeria. Afr Health Sci 2009; 9(4):227-33.

[45] Loto OA, Oyapero A, Awotile AO, Adenuga-Taiwo OA, Enone LL, Menakaya IN. An update on the relative vulnerability of the first and second permanent molars to caries in urban Nigerians. J Int Oral Health 2019; 11(5):274-9. https://doi.org/10.4103/jioh.jioh_9_19 